\title{
Extraction and Characterization of Omega-3 Fatty Acid from Catfish Using Enzymatic Hydrolysis Technique
}

\author{
N.I. Iberahim ${ }^{1}$, Z. Hamzah ${ }^{1}$, Y.J. Yin ${ }^{1}$, and K.S.A. Sohaimi ${ }^{1}$ \\ ${ }^{1}$ Faculty of Engineering Technology, Universiti Malaysia Perlis, Sungai Chuchuh, 02100 Padang Besar, Perlis, Malaysia.
}

\begin{abstract}
Extraction of Omega-3 fatty acid from Catfish using enzymatic hydrolysis techniques are expected to be more economically possible techniques due to the uses of enzyme with the characteristic of reusable, environmental friendly and less energy required for large-scale production. Malaysian like to consume Catfish in their daily diet. Thus, it is very popular among farmers in Malaysia. Omega-3 polyunsaturated fatty acid have many benefit to human health. Based on research, EPA and DHA can reduce the risk of heart disease by regulate the blood coagulation. The main purpose of this research is to extract the Omega-3 polyunsaturated fatty acid by using enzymatic hydrolysis method. Enzymatic extraction technique by using Alcalase was used to extract the Catfish oil. Then, lipase was used to concentrate the omega-3 polyunsaturated fatty acid. Peroxide value and acid value were used to determine the Catfish oil quality. Optimization using DOE verify that the highest percentage of oil yields at $51{ }^{\circ} \mathrm{C}, 0.91 \%$ enzyme concentration and 155 minute incubation time. Finally, there are two types of omega-3 polyunsaturated fatty acid can be found in Catfish oil which is EPA and ALA.
\end{abstract}

\section{Introduction}

Catfish is one of the diverse group of ray-finned fish that mostly found in the freshwater of Malaysia. Normally, catfish is grey in colour and scaless. People can identify catfish by their long whiskers-like barbels extend from their mouth. Catfish may consist up to four pairs of barbels. Besides that, catfish also consists of flattened broad head and hollow bony leading ray on their dorsal and pectoral fins. They are usually bottom feeder and they like to prey at night. Catfish are carnivores so they mostly prey small fish, worms, frogs, insects, and newts that present in the river [1].

Freshwater pond culture had been grown rapidly due to the development of aquaculture in Malaysia recently. Catfish is one of the fish that is popular among farmers because its easiness in culture, hardiness, high reproduction rate, and high growth rates. Catfish can survive in varying environment due to their hardiness. Therefore, farmer only needs to use plastic bowl to culture catfish. Catfish also had excellent nutritional value and market value in Malaysia.

Based on the Food and Agriculture Organization (FAO), Malaysia categorized as one of the top fishconsuming countries in Asia which above $40 \mathrm{~kg} / \mathrm{capital} /$ years almost double the average in Thailand and China. Omega-3 fatty acid which is a polyunsaturated fatty acid is one of the significant nutrition in commercial Catfish [2].

Omega-3 fatty acid mostly can be obtained in fish oil. Omega 3 fatty acids is an essential fats that consist of a chain of carbon, hydrogen, and oxygen atoms. It is also categorized as polyunsaturated fatty acid which consists of more than one double bond. Polyunsaturated fatty acid only can be obtained from diet because human body cannot synthesis polyunsaturated fatty acid. Basically, there are two types of omega-3 fatty acids that can be found in fish oil, namely Eicosapentaenoic acid (EPA) and Docosahexaenoic acid (DHA). Based on the research, it is shown that patients with the $\mathrm{V}$ hyperlipidemia, fish oil supplements is used as one of the important therapeutic option [3].

There are many benefits of EPA and DHA to human. EPA and DHA both help to regulate blood coagulation and control inflammatory responses. According to the information obtained, EPA used to treat high risk pregnancies, heart disease, depression, diabetes, Alzheimer's disease, high blood pressure, and cystic fibrosis [4]. EPA is modified to become antidepressants to treat depression. Besides that, EPA combined with RNA and L-arginine is used to heal wounds after surgery and reduce the time of recovery of the patient. DHA is important for maintain brain health in which researchers determine that DHA provides brain-boosting benefits in newborn baby and senior citizen. Alzheimer's disease patients consist of low levels of DHA in the neurons of hippocampus. Hippocampus is the disease affected part of the brain. Prasad and co-workers from the University of Kentucky prove that phosphatidyl-ethanolamine contains large amount of DHA that can reduce those brain region that is affected by this diseases [5]. In market, pregnancy woman is also recommended to take 
milk with high DHA levels to improve brain development of fetus [6].

There are many methods that can be used to extract catfish oil. Enzymatic hydrolysis is one of the methods that uses suitable enzyme and water to extract catfish oil. The benefit of this method is can obtain large amount of oil compared to others method. This is due to the present of enzymes that can catalyze the hydrolysis reaction process

\section{Material and method}

\subsection{Raw materials}

The raw material used in this experiment was taken from Pusat Pengumpulan Hasil-Hasil Perikanan Air Tawar, Pejabat Perikanan Air Tawar, Perlis. The Catfish collected at this place was Clarias Gariepinus species. The sample was homogenized and kept in sealed plastics bags in freezer at $-20^{\circ} \mathrm{C}$.until further used.

\subsection{Experiment design}

This experiment operated in two main sections:

- Optimized the optimum condition for extraction of the highest percentage of oil yields.

- Concentrated the omega-3 fatty acid from fish oil.

In the first section, enzymatic hydrolysis was carried out in order to obtain fish oil. Three parameter were screened by using a DOE software Full Factorial Design to ensure that the parameter chosen was significant which can affect the amount of fish oil. The experiment was carried out by using temperature in a range between $35^{\circ} \mathrm{C}-55^{\circ} \mathrm{C}$. The second parameter is enzyme concentration. $0.5 \%$ $2.5 \%$ unit of enzyme was used to collect fish oil in this experiment. Lastly, incubation time is one of the important parameter in this experiment. Time of incubation that decide to investigate in this experiment was between $60 \mathrm{~min}-80 \mathrm{~min}$. In section 2, a commercial Candida rugose lipase was used to concentrate the amount of Omega-3 fatty acid in the fish oil. The recovery oil yields before and after concentrated by lipase enzyme were then analyzed by FTIR and GC.

\subsection{Enzymatic extraction of fish oil}

$50 \mathrm{~g}$ of minced fish sample was transferred into $250 \mathrm{ml}$ of conical flask. Preheated water bath was used to heat the sample at $95^{\circ} \mathrm{C}$ for $5 \mathrm{~min}$. Then, $100 \mathrm{ml}$ of distilled water was added into the conical flask. The $\mathrm{pH}$ of the sample mixture must be maintained at $\mathrm{pH}$ 7.0. The $\mathrm{pH}$ of the sample mixture was adjusted by adding $3 \mathrm{M} \mathrm{NaOH}$. Next, the conical flask was placed into water bath shaker at desired temperature. Enzymatic hydrolysis was settling out when adding Alcalase enzyme into the conical flask. Different load of Alcalase enzyme was used to identify how concentration of enzyme effect on the amount of fish oil production. The enzymatic hydrolysis reaction was carry out in water bath shaker at $120 \mathrm{rpm}$ for desired incubation time. Then, heating the sample at $95^{\circ} \mathrm{C}$ for 5 min to denature the structure of enzyme. The top two layer oil and emulsion which then transferred to another centrifuge tube. $2 \mathrm{ml}$ of $0.9 \% \mathrm{NaCl}$ were added into the centrifuge tube. Another round of centrifugation process was carried out at $3000 \mathrm{rpm}$ for $15 \mathrm{~min}$. The upper layer collected and the lower layer was discard. Then, anhydrous sodium sulfate were added into the top layer have been collected. Then, the oil remain was collected and the anhydrous sodium sulfate was discarded.

\subsection{Optimization of enzymatic extraction process}

$4 \mathrm{~g}$ of fish oil were weighed by using weighing balance and transferred into a $50 \mathrm{ml}$ conical flask. The $\mathrm{pH}$ of the fish oil sample was maintained at $\mathrm{pH} 7.0$ by added $6 \mathrm{ml}$ of $1 \mathrm{M}$ phosphate buffer. Then, 800 unit of lipases was added into the phosphate buffer and transferred into the conical flask with oil sample. The flask was put into water bath shaker at $35^{\circ} \mathrm{C}$ for 20 hours. After that, $2 \mathrm{ml}$ of methanol was added to the sample mixture to stop the enzymatic hydrolysis reaction. Fatty acid was released during enzymatic hydrolysis. Thus, desired amount of $0.5 \mathrm{~N} \mathrm{KOH}$ added to neutralize the fatty acid released. The sample mixture was transferred into separator funnel and mixed with $100 \mathrm{ml}$ of hexane and $50 \mathrm{ml}$ of distilled water. The upper layer consists of hexane and acylglycerols. The concentrated oil was kept in universal bottle under refrigerator to undergo further analysis.

\subsection{Fatty acid methyl ester (FAME) analysis}

The major components of acylglycerols extracted from the previous experiment was fatty acids. Basically, FAME were prepared by base or acid catalyzed esterification. Sample before and after concentrated was used to prepare FAME analysis. 0.1g of lipids from previous experiment were weighted by weighing balance and transferred into a centrifuge tube. Then, esterification reaction was started by adding $1.5 \mathrm{ml}$ of methylene chloride, $0.01 \%$ BHT and $3.0 \mathrm{ml}$ of Hilditch reagent into the tube. Heating block was used to place the centrifuge tube for 1 hours. After 1 hours, the tube was cool to room temperature. Next, $1 \mathrm{ml}$ of distilled water and $1.5 \mathrm{ml}$ of hexane added into the tube. The top layer was transferred to the Tube 2 in each repeat experiment. Tube 2 was closed with cap then ready to vortex for $30 \mathrm{~s}$ and centrifuge for $2 \mathrm{~min}$. The upper layer of Tube 2 transferred to another new tube which called tube 3 . Anhydrous sodium sulphate was added to Tube 3 to removed excess water. The FAME produced will undergoes GC-MS analysis.

\subsection{Determination of acid value of oil sample}

Two $250 \mathrm{ml}$ conical flask was prepared to carry out this experiment. First, $125 \mathrm{ml}$ of 1:1 toluene-isopropyl alcohol and $2 \mathrm{ml}$ of phenolphthalein indicator was added into the $250 \mathrm{ml}$ conical flask. The solution mixture in the first conical flask was neutralized with $0.1 \mathrm{~N}$ potassium hydroxide solution until a faint but permanent pink colour 
appear. 0.5-2.5 g of oil sample was weight by using weighing balance and transfer into another empty conical flask. Then, measure $125 \mathrm{ml}$ of neutralized solvent mixture in the first conical flask was measured and pour into the conical flask with oil sample. Then, oil sample and the solvent were mixture carefully. Next, the mixture was titrated with $0.1 \mathrm{~N} \mathrm{KOH}$ solution until pink colour can be observed. The volume of $0.1 \mathrm{~N} \mathrm{KOH}$ solution that used to titrate the mixture solution must be measure. The acid value was calculated by (1):

$$
\text { Acid value }=((\mathrm{A}-\mathrm{B}) \times \mathrm{N} \times 56.1) / \mathrm{W}
$$

Where, $A=m l$ of standard alkali used in the titrating the sample, $B=m$ of standard alkali used in the titrating the blank, $\mathrm{N}=$ normality of standard alkali, $\mathrm{W}=$ grams of sample

$56.1=$ molecular weight of $\mathrm{KOH}$ in grams

\subsection{Determination peroxide value of oil sample}

Peroxide value of oil sample defined as the amount of peroxide oxygen per $1 \mathrm{~kg}$ of fat or oil. First, $5 \mathrm{~g}$ of oil sample weighted by weighing balance. Then, the oil sample was transferred into $250 \mathrm{ml}$ conical flask. After that, measuring cylinder used to measure $30 \mathrm{ml}$ of $3: 2$ acetic acid-chloroform. Then, 3:2 acetic acid-chloroform transferred into the flask and swirl. $0.5 \mathrm{ml}$ potassium iodide solution was added and the solution allowed to stand and put into a shaker for $1 \mathrm{~min} .30 \mathrm{ml}$ of distilled water was measured and transferred into a flask. Titration carried out with $0.1 \mathrm{~N}$ sodium thio-sulfate until the mixture solution change to yellow colour. $0.5 \mathrm{ml}$ of starch indicator solution was added into a solution. Titration was continued carry out until the solution turns to colourless. The same condition solution were prepared but without adding oil sample as a blank solution. The peroxide value can be determined by (2):

$$
\text { Peroxide value }=((\mathrm{S}-\mathrm{B}) \times \mathrm{N} \times 1000) / \mathrm{W}
$$

Where, $\mathrm{B}=\mathrm{ml}$ of standard potassium thiosulfate used for titration of blank, $\mathrm{S}=\mathrm{ml}$ of standard potassium thiosulfate used for titration of sample, $\mathrm{N}=$ normality of sodium thiosulfate solution $1000=$ per $1000 \mathrm{~g}$ of sample, $\mathrm{W}=$ gram of sample.

\section{Results and discussions}

\subsection{Parameter and range set in DOE software}

Second Full Factorial Design was used to screen the parameter. Three parameter were undergo screening which are temperature, enzyme concentration, and incubation time. The response was taken by the average percentage oil yields obtained. Table 1. represented the result provided by ANOVA analysis. Based on the result of ANOVA, temperature, enzyme concentration, and incubation time have the "Prob $>\mathrm{F}^{\text {" value less than }}$ 0.0500 . Thus, temperature, enzyme concentration, and incubation time is the significant parameter which will affect the oil yields percentage obtained from the experiment.

Table 1. Screening result by anova.

\begin{tabular}{|c|c|c|}
\hline Parameter & Prob $>$ F & Significantly \\
\hline Temperature & 0.0045 & Significant \\
\hline Enzyme Concentration & 0.0059 & Significant \\
\hline Incubation Time & 0.0107 & Signifcant \\
\hline
\end{tabular}

\subsection{RSM-ANOVA analysis}

Based on the multiple regression analysis of ANOVA, a quadratic model 3 was generate which is correspond to the oil yields percentage and various process variables.

Oil Yields $(w t \%)=14.67+0.55 \mathrm{~A}+0.40 \mathrm{~B}+0.31 \mathrm{C}+$ $0.41 \mathrm{~A} 2+(6.553 \mathrm{e}-0.03) \mathrm{B} 2+0.070 \mathrm{C} 2-0.24 \mathrm{AB}+$ $0.63 \mathrm{AC}-0.35 \mathrm{BC}$

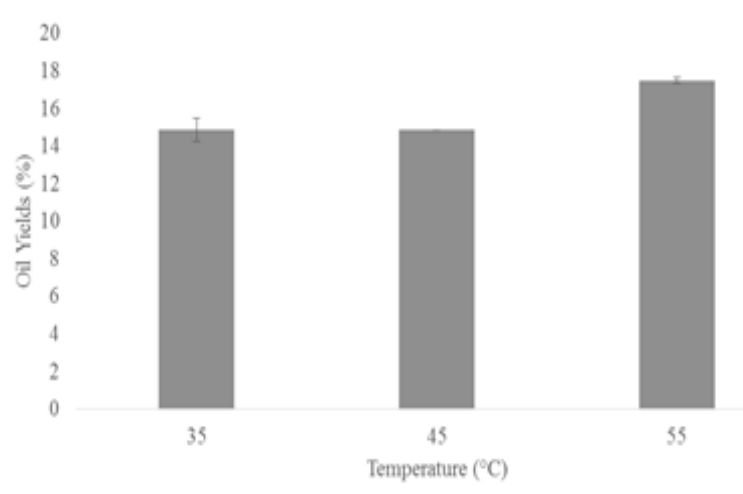

Figure 1. Bar chart of percentage oil yields versus temperature at $120 \mathrm{~min}$ and $1.5 \%$ enzyme concentration.

According to Figure.1, the percentage of oil yields is the highest at $55^{\circ} \mathrm{C}$ which is $17.5062 \pm 0.1606 \%$. However, the percentage of oil yields almost the same at $35^{\circ} \mathrm{C}$ and $45^{\circ} \mathrm{C}$ which is $14.8537 \pm 0.6163 \%$ and $14.8527 \pm 0.0073 \%$ respectively. This indicated that Alcalase is thermostability, it is not active at low temperature. When the temperature is low, it does not provide enough energy for the Alcalase to bind with the substrate. However, when the temperature increase to $55^{\circ} \mathrm{C}$, the percentage of oil yields also increase. This is because, the substrate molecule gain energy and will move faster at high temperature. Hence, increase the temperature will increase the frequency of collision between enzyme active site and substrate [7]. Based on the research of Akika Bura Mohanarangan, Alcalase have the optimum temperature between $50-60{ }^{\circ} \mathrm{C}$ [8]. Thus, our result obey this statement because Alcalase have the highest activity at $55^{\circ} \mathrm{C}$ when compared with others temperature.

\subsection{Effect of enzyme concentration}


Enzymatic extraction of Catfish oil start by using the enzyme, Alcalase. The amount of enzyme use in the extraction process strongly influences the percentage of oil yields. The concentration of enzyme added into the enzyme reaction were $0.5 \%, 1.5 \%$, and $2.5 \%$ by $50 \mathrm{~g}$ of minced Catfish raw materials.

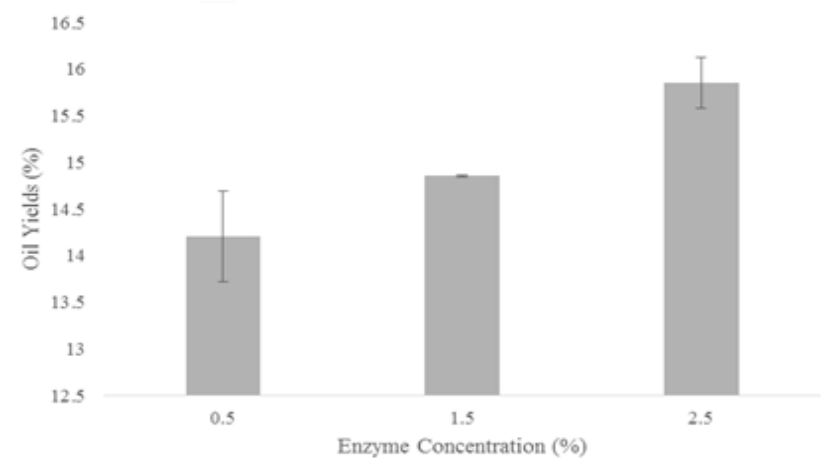

Figure 2. Bar chart of percentage oil yields versus enzyme concentration incubated at $45^{\circ} \mathrm{C}$ and 120 minutes.

Runs 1, 6, and 7 shows that the percentage of oil yields increase linearly when the enzyme concentration increase in the extraction process. Based on Figure 4.4, when the enzyme concentration use in enzymatic extraction was $2.5 \%$ obtained the highest oil yields which is $15.8486 \pm 0.274 \%$. When the enzymatic concentration increase, more substrate can be binds to the enzyme. Thus, more free fatty acids will be formed and increase the oil yields percentage. According to research, substrate concentration acts as the limiting factors for the enzymatic extraction reaction. When the substrate concentration use is lower than the enzyme concentration, increase the enzyme concentration will not affect the percentage of oil yields.

\subsection{Effect of incubation time}

In the optimization process, the range of incubation time were set between 60minute to 180 minutes and observe the effect of incubation time in enzymatic extraction process. Table shows that the $\mathrm{F}$ value of incubation time is smaller than temperature and enzyme concentration. This means that incubation time slightly affect the percentage of oil yields.

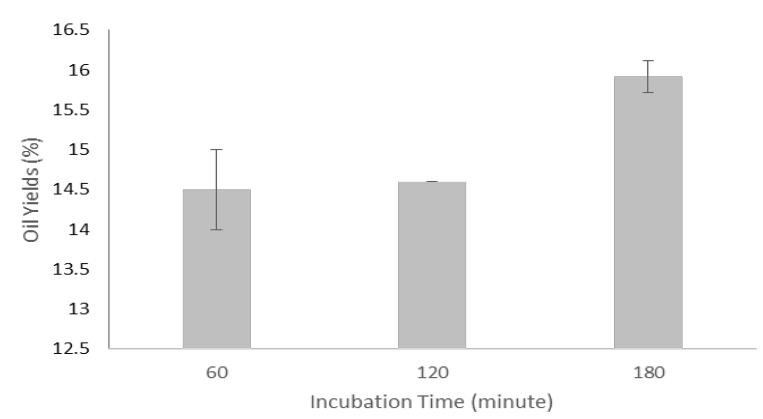

Figure 3. Bar chart of percentage oil yields versus incubation time at $45^{\circ} \mathrm{C}$ and $1.5 \%$ enzyme concentration.
When the incubation time increase from 60 minute to 180 minute, the percentage of oil yields obtained increase from $14.4944 \pm 0.5046 \%$ to $15.9186 \pm 0.2012 \%$. Based on the research, when incubation time increase the rate of hydrolysis also increase. This is because enzyme can react more extensively with substrate and more product will be generated.

\subsection{Optimization process parameter}

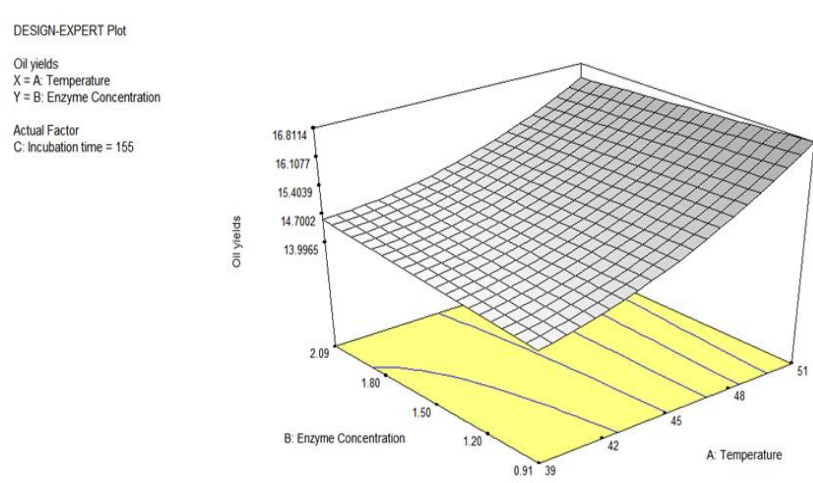

Figure 4: 3D surface of the optimum condition to extract the highest oil yields.

The purpose of optimization process is to identify the optimum condition for each parameter to achieve the highest oil yields percentage in the enzymatic extraction process. The software used to help determine the optimize point is Response Surface Methodology with Central Composite Rotatable Design. The individual process parameter and interaction between parameter was used to analyze and determine the optimum point in enzymatic extraction process. The software provide 10 solution that can achieve high percentage oil yields within the limit. The software predicted that the best solution will produced the highest oil yields percentage $16.8113 \pm 0.906 \%$ was $0.91 \%, 51^{\circ} \mathrm{C}$, and 155 minute. Then, actual experiment was carried out to valid that the optimum point provided by the process is accurate. The actual experiment was run in two times and obtained the average percentage of oil yields. The average percentage oil yields of the actual experiment was $16.5858 \pm 0.0694 \%$.

\subsection{Functional group FTIR}

FTIR is the instrument that used to characterize the functional group of the Catfish oil. Spectrum TwoTM FTIR Spectrometer by Perkin Elmer was used to analysis the Catfish Oil sample before and after concentrated by lipase. FTIR Spectrophotometer by Perkin Elmer was equipped with ATR and DTGS (Deuterated Triglycine Sulfate) detectors to measure the IR spectra of Catfish oil liquid sample. The background of the software was collected before analysis the sample. Micropipette was used to pipette 40ul of sample and placed on the ATR crystal to undergo analysis. The spectra wavelength was set as $4000 \mathrm{~cm}-1$. Perkin Elmer Spectrum Version 10.5.2 was used to obtained database buildings and band assignments.

The Catfish oil before undergoes lipase concentrated consists of carboxylic acids, alkanes, saturated aliphatic, 
aliphatic methyl, methyl, alcohol, methylene, and phosphorous functional group [9][10]. However, the Catfish oil after undergoes lipase concentrated consists of alkanes, saturated aliphatic, aldehydes, aliphatic methyl, alcohol, phosphorous, and methylene compound. The knowledge from chemistry describes that fish oil is in the form of triglycerides. Triglycerides is the compound that made up of three ester functional group. In the FTIR spectra shows peaks of $1743.00 \mathrm{~cm}$ and $1743.08 \mathrm{~cm}$ which represent the present of ester group in the sample. Thus, in the sample consists of triglycerides compound. Besides that, FTIR spectra peaks $1117.49 \mathrm{~cm}, 1096.71 \mathrm{~cm}$, and $1117.48 \mathrm{~cm}$ indicated the present of glycerol in both sample.

When triglycerides undergoes hydrolysis will produce glycerol and three free fatty acids chain. Moreover, the peaks of $3007.37 \mathrm{~cm}$ and $1235.95 \mathrm{~cm}$ represent carboxylic group in the free fatty acids of the sample. Fatty acid chain in the triglycerides are made up of long chain of hydrocarbon. Mostly, they consists of even number of carbon atoms which from 4 to 36 carbon atoms [11]. Aliphatic methyl functional group determine by $1463.69 \mathrm{~cm}$ and 1464.76 peaks and the methylene rocking vibration $720.10 \mathrm{~cm}$ and $721.65 \mathrm{~cm}$ valid the present of long and linear aliphatic hydrocarbon chain in the Catfish oil [12]. Thus, there will be present of methyl group in the fatty acid chain. If there is the single bond between the carbon atoms is called saturated fatty acids. On the others hand, there is the double bond between some of the carbon atoms is called unsaturated fatty acids.

Based on the spectrum diagram we obtained from FTIR analysis, $2921.65 \mathrm{~cm}$ and $2922.05 \mathrm{~cm}$ peaks represent alkenes functional so determine there is the unsaturated fatty acid in the Catfish oil. The alkanes group was used to prove the present of saturated fatty acid in the Catfish oil. Besides that, $1159.13 \mathrm{~cm}$ and 1163.54 peaks determine the present of phosphorous compound [10]. This analysis valid that the Catfish oil consists of phospholipid because there is the present of phosphate group in the fatty acid chain. The main function of lipase was used to concentrate the polyunsaturated fatty acids such as EPA and DHA. Lipase will used to break the ester bond between glycerol and monounsaturated fatty acid and saturated fatty acid. The peaks of $1743.00 \mathrm{~cm}$ and $1744.08 \mathrm{~cm}$ is in the range that indicated the present of triglycerides ester bond. The sample before concentrate by lipase $1743 \mathrm{~cm}$ is higher than $1744.08 \mathrm{~cm}$. This is because most of the triglycerides ester bond hydrolyses by lipase to release free fatty acids chain [14].

\subsection{FAME analysis}

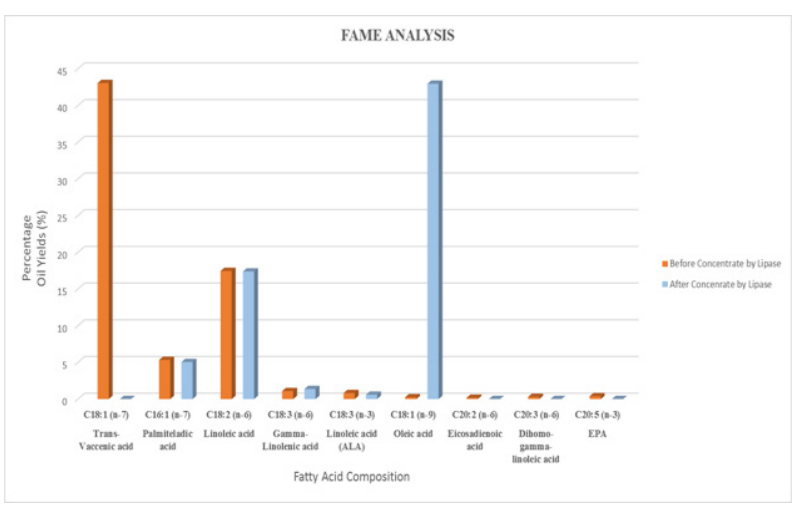

Figure 5. Fatty acid composition of catfish oil.

The Catfish oil that in the triglycerides structure undergoes saponification to produce glycerol and free fatty acids. Then the free fatty acids will undergoes methylation with methanol and derivatization in the methyl ester form and become fatty acid methyl ester (FAME). Gas Chromatography only can separate the fatty acid composition in the methyl ester form. This equipment separate the fatty acid based on degree of unsaturation and carbon number in the fatty acid chain. According to the analysis, Catfish oil consists of saturated fatty acid, monounsaturated fatty acid, and polyunsaturated fatty acids.

There are two types of omega-3 polyunsaturated fatty acid can be found in Catfish oil which are linoleic acid (ALA) and Eicosapentaenoic acid (EPA). Moreover, omega-6 polyunsaturated fatty acid also found in the Catfish oil. For example, Dihomo-gamma-linoleic acid, Eicosadienoic acid, and Gamma-linoleic acid. Then, the highest percentage of fatty acid composition found in Catfish oil are monounsaturated fatty acids which is $48.4136 \%$ before concentrated by lipase and $47.9947 \%$ after concentrate by lipase.Besides that, the lowest fatty acid composition percentage are polyunsaturated fatty acid which is $20.3218 \%$ before concentrate by lipase and $19.3249 \%$ after concentrate by lipase.

The result determine that after the Catfish oil concentrate by lipase, the amount of polyunsaturated fatty acid decrease. This might due to auto-oxidation and photo-oxidation of the oil. Research also prove that polyunsaturated fatty acids more likely to undergoes oxidation. When polyunsaturated undergoes oxidation will release hydroperoxide and this hydroperoxide further oxidizes will become ketones or aldehydes compound [13]. FTIR analysis in Table 1 shows the present of ketones functional group. Hence, this verified that the polyunsaturated fatty acid in the Catfish oil after concentrate by lipase reduce because of oxidation.

\subsection{Acid value}

The definition of acid value is the amount of potassium hydroxide in milligram need to neutralize the free fatty acid per one grams of oil. Thus, it can be used to predict the amount of free fatty acids present in the Catfish oil. Based on research, the lower the acid value, the higher the quality of oil. Food and Science department recommend the suitable acid value range of oil that can 
consumed by human was lower than $5 \mathrm{mg} \mathrm{KOH} / \mathrm{g}$. There are many factors can influenced the acid value of oil such as extraction procedure, freshness of raw materials, and oil composition. The extraction procedure that used to extract the Catfish oil was optimum condition of enzymatic extraction. According to the data obtained, the acid value of Catfish oil extract by optimum condition of enzymatic extraction was $2.244 \mathrm{mg} \mathrm{KOH} / \mathrm{g}$. This justify that the optimum condition of enzymatic extraction that optimize in the previous step was able to generate good quality of Catfish oil. After that the Catfish oil were undergoes lipase hydrolysis to separate and enrich the content of EPA and DHA in the Catfish oil. The acid value that we obtained from the experiment was $154.836 \mathrm{mg} \mathrm{KOH} / \mathrm{g}$. This valid that lipase hydrolysis the bond between glycerol and fatty acids in triglyceride. The higher the acid value, the higher the amount of free fatty acid hydrolyses by lipase.

\subsection{Peroxide value}

Table 2. Peroxide value of catfish oil before and after concentrate by lipase.

\begin{tabular}{|c|c|}
\hline Sample & Peroxide Value (Meq/g) \\
\hline $\begin{array}{c}\text { Catfish oil before concentrate } \\
\text { by lipase }\end{array}$ & 6.67 \\
\hline $\begin{array}{c}\text { Catfish oil after concentrate } \\
\text { by lipase }\end{array}$ & 20.00 \\
\hline
\end{tabular}

The definition of peroxide value is the amount of hydroperoxides in an oxidized oil. When oil undergoes oxidation will produce hydroperoxides. Based on the research, the lower the peroxide value, the better the quality of oil. There are many factors can cause the increased of oxidation rate of oil such as moisture content, fatty acid composition, light intensity, oxygen availability and temperature. A good quality of oil will have a peroxide value between $2 \mathrm{Meq} / \mathrm{g}$ to $10 \mathrm{Meq} / \mathrm{g}$. The peroxide value that obtained from the optimum condition enzymatic extraction Catfish oil was $6.67 \mathrm{Meq} / \mathrm{g}$. This valid that the enzymatic extraction process able to produce good quality of oil and the temperature used does not faster the oxidation rate of Catfish oil.

However, after the Catfish oil concentrated by lipase the peroxide value increased up to $20 \mathrm{Meq} / \mathrm{g}$. Although the oil is incubated with nitrogen gas to prevent enter of oxygen gas and prevent oxidation but the incubation time is long, 24 hours. Some of the nitrogen gas might runoff and oxygen enter to triggers oxidation reaction. In addition, the more number of polyunsaturated fatty acid will cause fish oil extremely liable to oxidation. Hence, after lipase concentrate the Catfish oil increased the amount of polyunsaturated fatty acid, the peroxide value become higher.

\section{Summary}

Based on the screening data, the design verify that temperature, enzyme concentration, and incubation time have significant effect on the percentage of oil yields obtained by using enzymatic extraction process. The optimization result of this three parameter in the enzymatic extraction process were $0.91 \%$ enzyme concentration, $51^{\circ} \mathrm{C}$, and 155 minute. The predicted solution shows that oil yields achieved in this condition is the maximum which is $16.8113 \pm 0.906 \%$. Based on the spectra obtained in the FTIR analysis, Catfish oil before and after concentrate by lipase have many similar functional group such as carboxylic acid, alkenes, alkanes, ester, methyl, alcohol, phosphorous, and methylene group. However, the peaks of the ester bond decrease in the spectra after concentrate by lipase. This is because lipase hydrolyses the ester bond of triglycerides compounds.

In addition, that is the present of aldehydes group in the Catfish oil after concentrated by lipase. This verify that oxidation happens in Catfish oil. The quality of Catfish oil indicated by acid value test and peroxide value test. The acid value and the peroxide value of the Catfish oil before concentrated by lipase is $2.244 \mathrm{mg} \mathrm{KOH} / \mathrm{g}$ and $6.67 \mathrm{Meq} / \mathrm{g}$ respectively. The acid value and the peroxide value are in the recommended range that justify the Catfish oil extract by using optimum condition enzymatic extraction is in a good quality. On the others hand, the Catfish oil after concentrated by lipase increased in acid value and peroxide value. Gas Chromatography-Mass Spectroscopy was used to analysis the fatty acid composition of Catfish oil. The analysis shows that there are two types of omega-3 polyunsaturated fatty acid found in Catfish oil which is EPA and ALA.

\section{References}

1. G. Elson, "Feeding Catfish," in Catfish: Everything about Natural History, Purchase, Health Care, Breeding, p. 95, (2003).

2. E. Teh, "Fisheries in Malaysia: Can resources match demand?," no. June, (2012).

3. "Lutein + zeaxanthin and omega-3 fatty acids for age-related macular degeneration: the Age-Related Eye Disease Study 2 (AREDS2) randomized clinical trial., ”JAMA, vol. 309, no. 19, pp. 2005-2015, May (2013).

4. R. J. W. Harry B. Rice, "EPA and DHA Omega-3s for heart and brain health: The evidence speaks for itself', 27, no. June, pp. 38-41, (2016).

5. M. Russell L. Blaylock, "DHA Supports Brain Development and Protects Neurological Function," Life Extension Magazine, (2008). [Online]. Available: http://www.lifeextension.com/magazine/2008/1/repo rt_dhafishoil/Page-01. [Accessed: 15-Mar-2017].

6. M. L. Juber, B. A., Jackson, K. H., Johnson, K. B., Harris, W. S., Baack, "Breast milk DHA levels may increase after informing women: a community-based cohort study from South Dakota USA," Int. Breastfeed. J., (2016).

7. J. Eed, "Factors affecting Enzyme Activity," Essai, 10, no. 10, pp. 48-51, (2012).

8. A. Bura Mohanarangan, "Extraction of Omega-3 Fatty Acids From Atlantic Herring (Clupea harengus)," no. November, (2012). 
9. C. Coury and A. M. Dillner, "ATR-FTIR characterization of organic functional groups and inorganic ions in ambient aerosols at a rural site," Atmos. Environ., 43, no. 4, pp. 940-948, (2009).

10. P. Arul Franco, N. Shenbagavinayagamoorthi, and A. Venkatesan, "FT-IR determination of free fattyacids in Sardinella longiceps fish oil and its performance and emission characteristics in DI diesel engine," Int. J. Chem Tech Res., 6, no. 7, pp. 3776-3783, (2014).

11. R. D. O'Brian, “Fats Oils, ” p. 766.

12. J. Vongsvivut, M. R. Miller, D. McNaughton, P. Heraud, and C. J. Barrow, "Rapid Discrimination and Determination of Polyunsaturated Fatty Acid Composition in Marine Oils by FTIR Spectroscopy and Multivariate Data Analysis," Food Bioprocess Technol., 7, no. 8, pp. 2410-2422, (2014).

13. T. O. Akanbi, J. L. Adcock, and C. J. Barrow, "Selective concentration of EPA and DHA using Thermomyces lanuginosus lipase is due to fatty acid selectivity and not regioselectivity," Food Chem., 138, no. 1, pp. 615-620, (2013).

14. T. Ling, "Oxidation of Polyunsaturated Fatty Acids and its Impact on Food Quality and Human Health," Adv. food Technol. Nutr. Sci., 1, no. 6, p. 135-142., (2015). 